Original Research Paper

\title{
Investigating the Effect of Intangible Factors (Human, Communication, Organizational, Information) on Brand Equity Case Study: Hotels in Isfahan
}

\author{
${ }^{1}$ Kaveh Ostad-Ali-Askari, ${ }^{2}$ Parisa Ashrafi, ${ }^{3}$ Amir Hossein Ashrafi, ${ }^{4}$ Hossein Gholami, \\ ${ }^{5}$ Morteza Soltani, ${ }^{6}$ Hossein Norouzi, ${ }^{7}$ Sona Pazdar and ${ }^{8}$ Shahide Dehghan \\ ${ }^{1}$ Department of Environmental Health Sciences, Faculty of Communication, Arts and Sciences, Canadian University Dubai, \\ Dubai, P. O. Box 117781, United Arab Emirates and Department of Civil Engineering, School of Engineering, American \\ University in Dubai, Dubai, P. O. Box 28282 United Arab Emirates and Department of Irrigation, College of Agriculture, Isfahan \\ University of Technology, Isfahan, 8415683111, Iran \\ ${ }^{2}$ Department of Architecture and Art, University of Kashan, Kashan, Iran \\ ${ }^{3}$ Department of Architecture and Urban Planning, Isfahan (Khorasgan) Branch, Islamic Azad University, Isfahan, Iran \\ ${ }^{4,6}$ Department of Civil Engineering, Isfahan (Khorasgan) Branch, Islamic Azad University, Isfahan, Iran \\ ${ }^{5}$ Department of Architectural Engineering, Shahinshahr Branch, Islamic Azad University, Shahinshahr, Iran \\ ${ }^{7}$ Department of Civil Engineering, Aghigh University, Shahinshahr, Isfahan, Iran \\ ${ }^{8}$ Department of Geography, Najafabad Branch, Islamic Azad University, Najafabad, Iran
}

Article history

Received: 17-06-2018

Revised: 04-08-2018

Accepted: 25-09-2018

Corresponding Author:

Kaveh Ostad-Ali-Askari

Department of Environmental

Health Sciences, Faculty of

Communication, Arts and

Sciences, Canadian University

Dubai, Dubai, P. O. Box 117781 ,

United Arab Emirates and

Department of Civil Engineering,

School of Engineering, American

University in Dubai, Dubai, P. O.

Box 28282 United Arab Emirates and Department of Irrigation,

College of Agriculture, Isfahan

University of Technology,

Isfahan, 8415683111, Iran

Email:ostadaliaskari.k@of.iut.ac.ir

kaveh.oaa2000@gmail.com

\begin{abstract}
The purpose of this study is to investigate the effect of evaluating the intangible factors (Human, Communication, Organizational and Information) on brand equity in hotels in Isfahan. A based research model was presented as the literature. The questionnaire of 24 items was conducted for this research and a sample of 130 executives and experts of hotels in Isfahan as a statistical society, was selected. The method of this research is applied in terms of objective and descriptive survey method from field branch. The reliability of the questionnaire was based on the original sample $(\alpha=0.81)$ and the return rate of the questionnaire was 0.84 . Meanwhile, using the PLS software, the model was tested. The results show that there is a positive relationship between the intangible communication and organizational factors and brand equity. And human and information capital do not have any effect on brand value. Progresses in knowledge technology and the emergence of online Public network sites have altered the procedure information is transferred. This event affects consumers as this simply available information could greatly affect the consumption intention.
\end{abstract}

Keywords: Brand, Value, Human, Factors, Communication Factors Organizational Factors, Factors Information

\section{Introduction}

The problems that marketing managers nowadays are: Their efforts to create and maintain a brand lacking planning due to lack of recognition of brand features and lack of understanding of the correct ways of managing brand names that cannot be Effectively link the product with the brand.

Most marketing managers or brand managers are well aware of marketing concepts such as recognizing customer needs, positioning, promotion and promotional activities and have a lot of experience in implementing them, but what makes them difficult to market products and services. It is that they cannot use marketing concepts to promote brand value. These are all because of the lack of recognition of the brand name as one of the most important intangible assets of the company and their withdrawal from the asset consists merely of what is thought to be and is palpable (Lasser et al., 1995). There are resources available for strategic positioning and that the time value is maximized when capabilities are used to exploit resources to create distinct competition and relative sustainable benefits. The brand manager needs his intangible capital (human capital, communication capital, organizational capital and Putting information into leverage to select brand elements (such as brand names, posters, packaging and slogans or logos) that are memorable, meaningful, portable, acceptable and supported, such as the design and application of the program Marketing and marketing activities to support, enhance and reinforce 
elective elements (Menzies, 2003). Otherwise, the brand manager should maintain the brand's position and equality among other competitors. Therefore, intangible capital of the brand manager is said to have an indirect effect on brand performance through brand management capabilities The present study provides a quantitative analysis in which intangible factors are considered as key factors affecting brand value. In the present study, a structural model was developed to investigate the relationship between these factors. This model shows the limitations of past research and researchers have tried to examine the relationship between these structures.

\section{Conceptual Framework of Research}

\section{Brand Value}

Today, the creation of strong brands, due to the extraordinary advantages that it creates, has become a marketing priority for many organizations. It creates strong brands for an identity firm in the market (Krishna and Harcelin, 2001).

In measuring the overall value of a brand, marketing researchers and researchers begin to test the concept of brand value, which brings to the general value brand name brought to the producer, retailers and consumers (Aaker, 1995). In 1989, the Brand Marketing Association defined the value added by name in the market through a margin of profit or a market share for the product. This added value by customers and other channel members can be considered as financial assets and a set of desirable relationships and behaviors (Yasin et al., 2007).

The brand's special brand value enables organizations to pay more for their brand in addition to retaining their market share. Brand equity boosts the efficiency of marketing programs and customer loyalty to the brand, reduces the costs and expenses of promotional activities and creates a platform for growth through brand development (Gilani and Mousavian, 2010. p: 104).

\section{Human Capital, Communication Capital, Enterprise Capital, Intelligence Capital}

The emphasis of organizations on human capital is based on the view that the market value of organizations is less dependent on tangible resources and is more dependent on intangible assets, especially human capital Attracting and retaining the best employees, however, is part of this equation. Organizations need to increase organizational learning and, by encouraging their employees to learn, increase their skills and abilities and create, with their support, an environment in which knowledge is created, shared, applied and dynamic environments for Continuous learning is created The organizational dimension in intellectual capital is defined as organizational capital (structural). Organizational capital is defined as the sum of assets that enable the organization's creativity. The mission of the company, the vision, the core values and the strategies and systems of work and internal processes of a company can be counted among these types of assets Organizational capital is one of the basic principles for the creation of learning organizations, even if the employees of an organization have sufficient and sufficient capabilities and capabilities. If the organizational structure is composed of a series of weak laws and systems, then these capabilities and staff talents for Creating value and having good organizational performance.

Information capital is one of the main and valuable resources of an organization's executives. As human resources, raw materials or finance in the production process play a role and value, but information is of special value. The greater the volume and complexity of the operation, the more important the information is. If we consider information as a resource, then, like other sources, it needs to be managed. Communication capital represents the power an organization has with regard to its intangible outside organization. These implications include knowledge of customers, suppliers, government, or industry associations. Developing and improving the component of communicative capital is more difficult than the other two components because it is far from the center of the organization.

\section{The Relationship between Intangible Factors and Brand Value}

There are resources available for strategic positioning and that the time value is maximized when the ability to use resources to create distinct competition and sustainable relative benefits extends managers to intangible capital (i.e., human capital, communication capital, organizational capital and information capital (Such as brand names, posters, packaging and slogans or logos) that are meaningful, portable, acceptable and supported, such as the design and implementation of marketing plans And marketing activities to support, enhance and reinforce elective elements brand. Otherwise, managers should maintain the brand's position and equality among other competitors. Therefore, it is said that the immense capital of the brand manager has a direct bearing on the brand's value (Fig. 1).

\section{Conceptual Model and Research Hypotheses}

According to the literature, the conceptual model of research is as follows.

\section{Research Hypotheses}

H1: Organizational capital has a significant impact on brand value.

H2: Relative capital has a significant impact on brand value.

H3: Human capital has a significant impact on brand value.

H4: Information capital has a significant impact on brand value. 


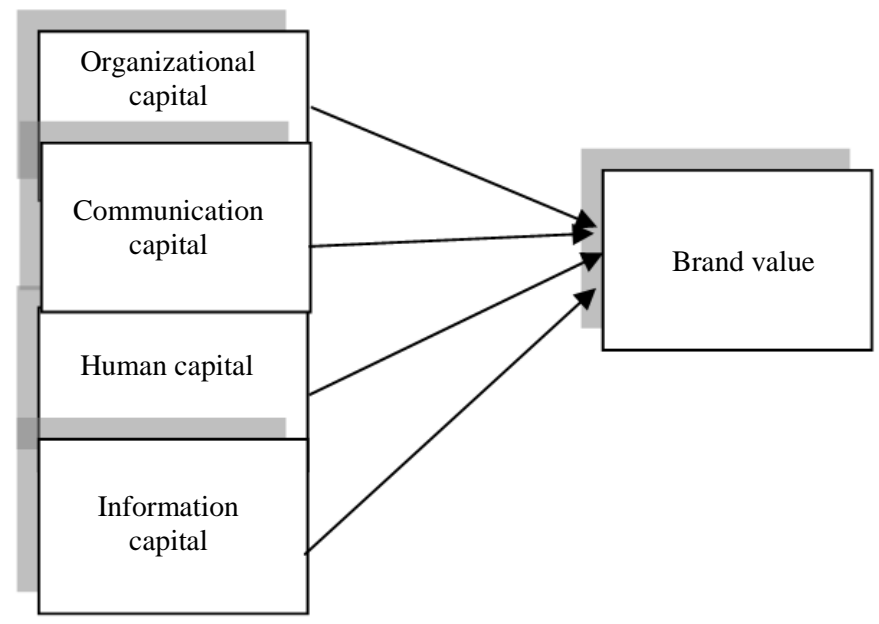

Fig. 1: The Conceptual Model of Research by

\section{Research Methodology}

This research is of descriptive and survey type in terms of purpose and purpose. This research, insofar as it addresses the attitudes of managers and sales and marketing experts and their views on the study of intangible factors (human, communication, organizational, information) and brand value, is in the domain of descriptive research and since The relationship between variables is considered correlation because the study of the relationship between variables is performed by correlation analysis. A total of 130 questionnaires were distributed among top managers and deputy directors of hotels, which received 109 questionnaires. Therefore, the return rate of the questionnaire is 0.84 .

Based on the Kolmogorov Smirnov test, the statistical population is not normal and it should be noted that for the validity of the opinion of the university professors and relevant community experts, it was assisted. Reliability was also calculated by Cronbach's alpha of 0.81 .

Investigating the hypotheses and the conceptual model of the research Since there are several independent variables in the present study, their effect on the.

The dependent variable is considered. The use of the structural equation model is necessary. In order to evaluate the proposed model, PLS software was used. According to the output of the LISREL software, the proposed model is presented in the following way, in which relations between variables and coefficients of each of them are presented.

The basic question raised is whether this model is a suitable model. The following criteria represent the strong fit of the model (Fig. 2).

\section{$R$ Squares or $R^{2}$}

A measure is used to connect the measurement section and the structural part of the structural equation modeling and indicates the effect that an exogenous variable has on an endogenous variable. The value of $\mathrm{R} 2$ is 75 hundredths.

\section{GOF Benchmark}

The general model consists of both parts of the measurement and structural model and, with its fit confirmation, the fit test is completed in a complete model and only one criterion is called JOF (GOF: Goodness Of Fit). The values of $0.01,0.25$ and 0.36 are described in weak, moderate and strong order, respectively:

$$
G O F=\sqrt{(\overline{\text { Communality }}) \times(\overline{\text { Rsquare }})}
$$

A gain of 0.39 for this criterion reflects the strong fit of the overall model.

\section{Redundancy Criterion}

The average of this benchmark is 42 hundredths and achieving a value of 0.42 for this criterion reflects the strong fit of the overall model.

\section{Significant Evaluation of Relationships}

In order to show the significance of each of the model parameters, $t$ statistics are used. This statistic derives from the ratio of the coefficient of each parameter to the standard deviation error of that parameter which should be greater than 2 in the test $t$ and $\mathrm{Z}$ greater than 1.96 in order to make these estimates statistically meaningful according to the output of PLS (Fig. 3) The calculated $t$ value of the human and information human capital is not greater than 2, so these paths are not confirmed.

The following Table 1 summarizes the results of the hypotheses and the fit of the model. 
Kaveh Ostad-Ali-Askari et al. / American Journal of Engineering and Applied Sciences 2021, 14 (3): 430.435 DOI: 10.3844/ajeassp.2021.430.435

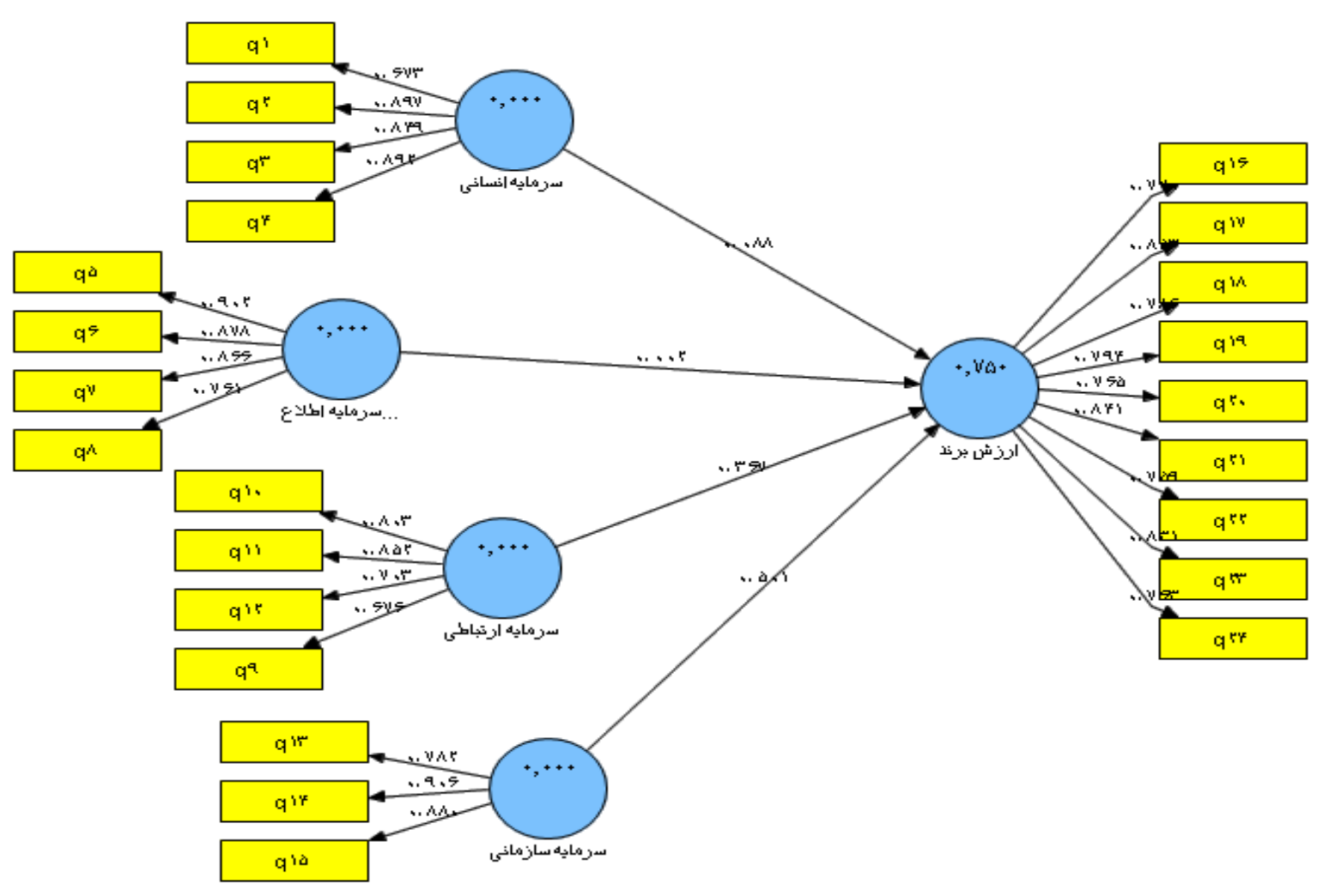

Fig. 2: Curve fit model illustrated by PLS ver. 2.1

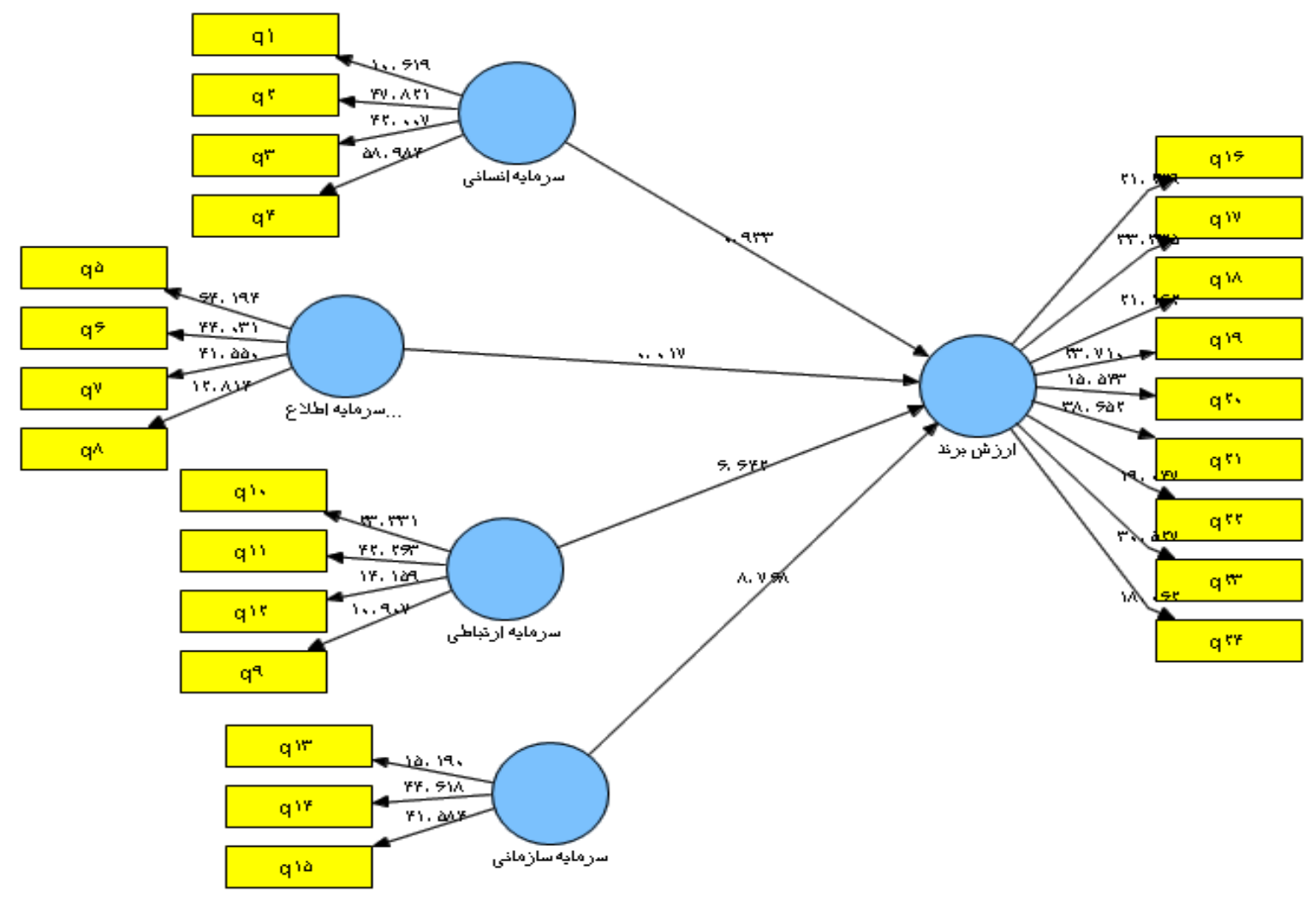

Fig. 3: The research relationships 
Table 1: Summary of the results of the hypotheses

\begin{tabular}{llll}
\hline & Pat & & \\
Assumptions & Coefficient & T-statistics & Result \\
\hline Human capital -> brand value & $08 / 0$ & $93 /$. & Reject \\
Enterprise Capital -> brand value & $50 / 0$ & $7 / 8$ & Confirmation \\
Communication Capital ->Brand Value & $36 / 0$ & $6 / 6$ & Confirmation \\
Information Capital ->Brand Value & $02 / 0$ & $002 / 0$ & Reject \\
\hline
\end{tabular}

\section{Discussion}

The results of this study confirm that organizational and communication capital is one of the prerequisites for brand equity. Organizational capital has a significant effect on the power of brand management. Reflects the consistency with Research that showed that organizational reputation and organizational capital have a direct and significant impact on brand equity dimensions. Communicative capital has a significant effect on brand managerial capabilities. It is consistent with), which showed that the failure and failure of a brand has a direct impact on the lack of capital of the relationship between executives and the organization of the value of the brand at home and abroad. This is because of the lack of a successful and effective relationship between marketing and brand managers. Organizations need to identify, measure and value their human capital in order to be able to operate and be effective in today's competitive and changing environment. Managers should increase their market share in the market by enhancing the skills and capabilities of the organization's staff in maintaining and updating the brand image, creating a unique value position, keeping brand equity consistent with the type of customer need. Therefore, we need to try to create a two-way interaction between the organization and the outside world, creating a two-way communication with its customers by creating a two-way interaction between the organization's brand and its customers, building, strengthening the brand's relationship with its customers and increasing brand integrity. Measurement parts are adjusted from available scales found in the retail literature. The measures are appraised for credibility, convergent reliability and discriminant reliability applying data collected in a survey of hotel's prospective customers in Iran. The article plans procedures to raise a brand effectively through online customer communities, as well as public tips for website and presentation in a manner beneficial to the members of their online communities. While there is a vital investigation stream that scrutinizes the branding of hotels and an increasing literature on hotel assessments, little is known about brand image in the context of online communications. This article develops an existing evaluation of the grand hotel. To figure out the economic value of computers, one must develop the traditional description of both the technology and its effects on advertisement hotels. This article considers the query: Does the physical environment of service transport settings affect customers' assessments of the service experiment and subsequent behavioral purposes? This article completes environmental psychology into a current extent of service quality to allow a fuller evaluation of the role of the sensible details of service delivery. Depend on hotel's consumer checks in three leisure service settings, the discoveries are that the sensible physical environment plays a vital role in generating excitement in leisure settings; excitement, in turn, plays a considerable role in assessing customers repatronage intentions and willingness to recommend.

\section{Conclusion}

There is a growing significance on building and managing brand equity as the elementary drivers of a hospitality hotel's success. Success in brand management outcaomes from understanding brand equity accurately and managing them to generate solid financial implementation. This article inspects the underlying aspects of brand equity and how they affect firms' implementation in the hospitality industry-in specific, luxury hotels. The consequences of this experiential study show that brand loyalty, comprehend quality and brand image is significant components of customer-based brand equity. An affirmative relationship was found to exist between the components of customer-based brand equity and the firms' efficiency in luxury hotels. A somewhat various outline was described from the relationship between the components of customer-based brand equity and firms' implementation in luxury hotels.

\section{Acknowledgment}

We thanks Isfahan University of Technology, Isfahan, Iran.

\section{Author's Contributions}

All authors equally contributed in this work. 


\section{Ethics}

This article is original and contains unpublished material. The corresponding author confirms that all of the other authors have read and approved the manuscript and no ethical issues involved.

\section{References}

Aaker, D. A. (1996). Building Strong Brands The Free Press. New York, 598-614.

Gilani, N., \& Mousavian, N. (2010). The effect loyalty to brand on value special brand bank from viewpoint customers Card electronic quarterly management industrial college science human university Loose Islamic the unit sanandaj.
Krishnan, B. C., \& Hartline, M. D. (2001). Brand equity: is it more important in services?. Journal of services marketing. https://www.emerald.com/insight/content/doi/10.11 08/EUM0000000005654/full/html

Lassar, W., Mittal, B., \& Sharma, A. (1995). Measuring customer-based brand equity. Journal of consumer marketing. doi.org/10.1108/07363769510095270

Menzies, M. (2003). Human capital development in research, science, and technology. FRST Human Capital Development Strategy.

Yasin, N. M., Noor, M. N., \& Mohamad, O. (2007). Does image of country-of-origin matter to brand equity? Journal of Product \& brand management. doi.org/10.1108/10610420710731142 